\title{
Pemilihan Network Monitoring System Berdasarkan Kajian Efektifitas Sistem Informasi dengan Pendekatan AHP: Studi Kasus pada "PT.TUV"
}

\author{
Eko Harli ${ }^{\# 1}$ \\ ${ }^{\text {\#} F a k u l t a s ~ T e k n i k, ~ M a t e m a t i k a ~ d a n ~ I P A, ~ U n i v e r s i t a s ~ I n d r a p r a s t a ~ P G R I ~}$ \\ Jl.Nangka No.58C Jagakarsa \\ ${ }^{1}$ ekoharli@gmail.com
}

\begin{abstract}
Abstrak - Jaringan komputer adalah sesuatu yang kompleks. Kompleksitas tersebut bukan hanya sebatas banyaknya device atau perangkat, tetapi juga begitu bervariasinya sistem dan teknologi yang ada di dalamnya, serta cakupan area jaringan yang yang luas. Infrastruktur yang handal sekalipun tidak bisa dijadikan jaminan bahwa fungsi jaringan dapat bekerja secara optimal tanpa didukung oleh monitoring atau pengelolaan yang baik. Semua kebutuhan tersebut dapat dipenuhi dengan program yang menyebut dirinya sebagai Network Monitoring System (NMS).NMS merupakan perangkat lunak yang fungsi utamanya adalah memonitor dan mengelola perangkatperangkat jaringan dengan tujuan agar reliability dan availability terjaga dan dapat secara dini diketahui anomaly atau terputusnya jaringan tersebut. Saat ini banyak sekali perangkat lunak yang handal serta mudah dalam penggunaannya sebut saja misalnya CiscoWork, HP OpenView, dan IBM Tivoli NetView. Hanya saja perangkat lunak tersebut cukup mahal, karena memang tergolong produk commercial. Untungnya ketersediaan produk NMS tidak sebatas commercial (propriety), tetapi juga banyak alternatif lain yaitu produk-produk yang tergolong mudah digunakan. Sayangnya, kebanyakan produk susah dalam implementasi, baik dari segi instalasi maupun konfigurasi, tetapi juga keterbatasan dalam jumlah node serta jenis yang dimonitor, meliputi perangkat jaringan, server, dan aplikasi. Metode pemilihan perangkat lunak NMS berdasarkan efektifitas Sistem Informasi ini didasarkan pada metode penelitian Oyku Alanbay melalui pendekatan AHP (Analitical Hierarchy Process) dengan software Expert Choice 2000. Penelitian ini diharapkan dapat menghasilkan metode yang tepat dalam menentukan perangkat lunak NMS berdasarkan efektifitas Sistem Informasi yang handal untuk digunakan sebagai tool monitoring jaringan, server, dan aplikasi untuk digunakan pada PT.TUV.
\end{abstract}

Kata kunci-Network Monitoring System, Metode Oyku Alanbay, Analitical Hierarchy Process, Expert Choice 2000.

\section{Pendahuluan}

Network Monitoring System (NMS) adalah sebuah layanan yang menggunakan alat, aplikasi dan perangkat yang digunakan untuk membantu manusia dalam mengatur dan mengamati jaringan. Dengan menggunakan alat Network Monitoring System (NMS) yang tepat akan sangat memudahkan pekerjaan seorang administrator atau pengguna dalam memantau dan merawat jaringan dilingkungannya.

PT. TUV mempunyai penyempurnaan sistem informasi secara terpadu antara bidang pemasaran dengan produksi dan administrasi keuangan.Sistem pencatatan transaksi berbasis komputer dilengkapi fasilitas network dalam area kerja namun jaringan sistem informasi yang ada sering kali terjadi gangguan yang mengakibatkan tersendatnya pelayanan yang optimal dan membuat pihak perusahaan merasa memerlukan monitoring untuk memantau sistem informasi yang berjalan.

Network Monitoring System (NMS) merupakan sebuah sub sistem dalam manajemen jaringan (Network Management System) yang melibatkan penggunaan perangkat lunak dan perangkat keras. Berdasarkan International Standards Organtations(ISO), aplikasi Network Monitoring System memiliki lima kriteria yaitu performance, managament, accounting managament, configuration managament, fault managament dan security managament[1]. Berdasarkan metode penelitian Oyku Alanbay dalam pengambil keputusan untuk menentukan software yang terbaik, maka penulis mengadopsi model yang telah dikembang kan Oyku Alanbay[2] dengan pendekatan metode AHP seperti pengembangan model Saaty[3].

\section{TEORI ANALYTICAL HIERARCHY PROCESS (AHP)}

Keputusan dapat diambil dari alternatif - alternatif keputusan yang ada. Pengambilan keputusan dapat dilakukan dengan dua kerangka kerja, meliputi pengambilan keputusan tanpa berdasarkan eksperimen, dilakukan dengan cara menyusun secara sistematis cara kerja umum sebelum mencari solusi bagi masalah yang diharapkan. Teori ini dikembangkan sejalan dengan pendekatan statistik di mana secara sederhana, keputusan yang dihasilkan diupayakan mempunyai pengaruh kesalahan seminimum mungkin[1]. 


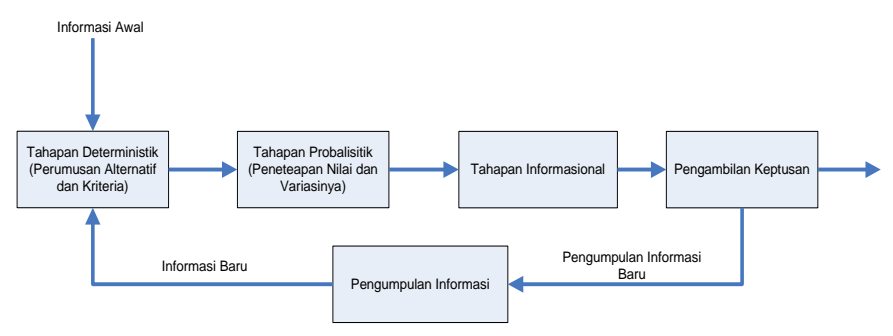

Gambar 1 Bagan Siklus Analisis Keputusan

Pada Gambar 1 dapat dijelaskan proses dari informasi awal yang dikumpulkan, kemudian dilakukan pendefinisian dan penghubungan variabel - variabel yang mempengaruhi keputusan pada tahap deterministik. Setelah itu dilakukan penetapan nilai untuk mengukur tingkat kepentingan variabel - variabel tersebut tanpa memperhatikan unsur - unsur ketidakpastian.

\section{A. Prinsip kerja $A H P$}

AHP merupakan suatu model pendukung keputusan yang dikembangkan oleh Thomas L. Saaty. Model pendukung keputusan ini akan menguraikan masalah multi faktor atau multi kriteria yang kompleks menjadi suatu hirarki[3].

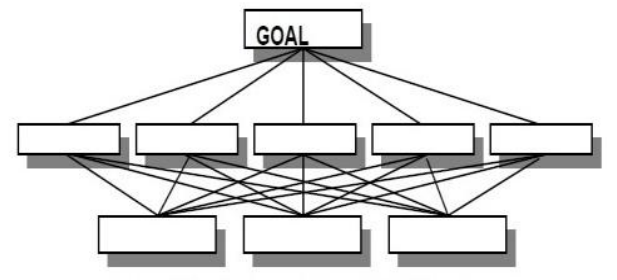

Gambar 2 .Representasi Hirarki Keputusan

Menurut Saaty (1993), hirarki pada gambar 2 dapat didefinisikan sebagai suatu representasi dari sebuah permasalahan yang kompleks dalam suatu struktur multi level dimana level pertama adalah tujuan, yang diikuti level faktor, kriteria, sub kriteria[4].

\section{B. Fungsi Utama $A H P$}

Beberapa keuntungan yang diperoleh bila memecahkan pesoalan pengambilan keputusan dengan menggunakan AHP dapat dijelaskan pada tabel 1 [1] :

Beragamnya produk software network monitoring untuk Sistem Informasi menyebabkan perlunya satu model untuk mengambil keputusan untuk mengetahui Software Network Monitoring System mana yang paling handal. Berdasarkan kebutuhan pada PT.TUV maka software monitoring yang akan diuji akan ditentukan oleh pihak perusahaan. Berikut adalah beberapa kelebihan dari software monitoring yang akan diuji yaitu software CACTI, NAGIOS, Paessler Router Traffic Graph (PRTG), OpenNMS dan DUDE.
TABEL 1.

KEUNTUNGAN MENGGUNAKAN AHP

\begin{tabular}{|c|c|}
\hline KEUNTUNGAN & KETERANGAN \\
\hline Kesatuan & $\begin{array}{l}\text { AHP memberikan satu model tunggal } \\
\text { yang mudah dimengerti, luwes untuk } \\
\text { aneka ragam persoalan tidak } \\
\text { terstruktur }\end{array}$ \\
\hline Kompleksitas & $\begin{array}{l}\text { AHP memadukan rancangan deduktif } \\
\text { dan rancangan berdasarkan sistem } \\
\text { dalam memecahkan persoalan } \\
\text { kompleks }\end{array}$ \\
\hline Saling Ketergantungan & $\begin{array}{lllr}\text { AHP dapat } & \text { menangani } & \text { saling } \\
\text { ketergantungan } & \text { elemen }- & \text { elemen } \\
\text { dalam suatu } & \text { sistem dan } & \text { tidak } \\
\text { memaksakan pemikiran linear } & \end{array}$ \\
\hline Penyusunan Hierarki & $\begin{array}{l}\text { AHP mencerminkan kecenderungan } \\
\text { alami pikiran untuk memilah-milah } \\
\text { elemen - elemen suatu sisatem dalam } \\
\text { berbagai tingkat berlainan dan } \\
\text { mengelompokkan unsur yang serupa } \\
\text { dalam setiap tingkat }\end{array}$ \\
\hline Pengukuran & $\begin{array}{l}\text { AHP memberi suatu skala untuk } \\
\text { mengukur hal - hal dan terwujud suatu } \\
\text { metode untuk menetapkan prioritas }\end{array}$ \\
\hline Konsistensi & $\begin{array}{l}\text { AHP melacak konsistensi logis dari } \\
\text { pertimbangan }- \text { pertimbangan yang } \\
\text { digunakan untuk menetapkan berbagai } \\
\text { prioritas. }\end{array}$ \\
\hline Sintesis & $\begin{array}{l}\text { AHP menentukan ke suatu taksiran } \\
\text { menyeluruh tentang kebaikan setiap } \\
\text { alternatif }\end{array}$ \\
\hline Tawar Menawar & $\begin{array}{l}\text { AHP mempertimbangkan prioritas - } \\
\text { prioritas relatif dari berbagai faktor } \\
\text { sistem dan memungkinkan organisasi } \\
\text { memilih alternatif terbaik berdasarkan } \\
\text { tujuan - tujuan mereka }\end{array}$ \\
\hline Penilaian dan Konsesus & $\begin{array}{l}\text { AHP tidak memaksakan konsensus } \\
\text { tetapi mensistensiskan suatu hasil yang } \\
\text { representatif dari berbagai penilaian } \\
\text { yang berbeda }\end{array}$ \\
\hline Pengulangan Proses & $\begin{array}{l}\text { AHP memungkinkan organisasi } \\
\text { memperhalus definisi mereka pada } \\
\text { suatu persoalan dan memperbaiki } \\
\text { pertimbangan dan pengertian mereka } \\
\text { melalui pengulangan. }\end{array}$ \\
\hline
\end{tabular}

\section{CACTI}

Cacti (Cactus) adalah aplikasi frontend dari RRDTool yang menyimpan informasi kedalam database MySQL dan membuat grafik berdasarkan informasi tersebut. Proses pengambilan data (lewat SNMP maupun skrip) sampai kepada pembuatan grafik dilakukan menggunakan bahasa pemrograman PHP.Cacti dapat digunakan untuk menyimpan graph, data sources, dan round robin archives ke dalam sebuah database. Aplikasi ini juga mendukung protocol SNMP, sehingga dapat digunakan untuk membuat traffic graph menggunakan MRTG.

Sebagai aplikasi monitoring server yang cukup kompleks, aplikasi ini sudah memiliki banyak fitur. Fitur yang dimiliki 
oleh Cacti diantaranya: Jumlah graph itern yang tidak terhingga, dapat didefinisikan untuk setiap graph secara optional dengan menggunakan $\mathrm{CDEF}$ atau data source dari Cacti dan Mendukung semua tipe graph dari (Round Robin Database) RRDTools, termasuk ARXAq STACK LINEU--31, GPRINT, COMMENT, VRULE, dan HRULE dan pada Data source dapat dibuat dengan memanfaatkan fungsi "create" dan "update", yang terdapat pada (Round Robin Database) RRDTool's dan Mendukung file RRD(Round Robin Database) dengan lebih dari satu data source, dan dapat menggunakan sebuah RRD (Round Robin Database) file yang disimpan di mana saja dalam suatu iocal file system dan Memiliki tree view yang memudahkan user untuk membuat "graph hierarchies", dan meletakkan graph dalam suatu tree dan Memiliki manajemen berbasis user, yang memudahkan administrator untuk menciptakan user, dan memberikan tipe permission yang berbeda antaruser[5].

\section{NAGIOS}

Nagios merupakan aplikasi untuk memonitoring network, host, dan service yang terdapat pada suatu jaringan. Aplikasi ini dapat menginformasikan kepada penggunanya, sebelum terjadi problem network di client atau end-user. Meski aplikasi ini didesain untuk berjalan pada sistem operasi Linux, tapi secara umum, aplikasi ini dapat berjalan pada kebanyakan varian NIX dengan sama baiknya.

Untuk proses kerjanya, monitoring daemon memeriksa secara berkala pada komputer host dan service yang telah didefinisikan dengan menggunakan eksternal "plugin", yang akan mengirim status informasi ke Nagios. Ketika terjadi suatu problem, daemon akan secara otomatis mengirimkan pesan ke administrator dengan menggunakan beragam cara yang dipilih (e-mail, instant messaging, SMS, dan sebagainya). Status informasi saat ini, log kejadian dan laporan, selanjutnya dapat diakses sepenuhnya dengan menggunakan web browser. Pihak Nagios sendiri, sudah menghasilkan beberapa produk hardware jaringan yang menggunakan Nagios sebagai aplikasinya. Beberapa produk seperti perangkat monitoring lingkungan, perangkat monitoring jaringan berbentuk router, perangkat mobile untuk menyampaikan pesan notifikasi, dan beberapa perangkat lainnya, telah di hasilkan oleh pihak Nagios.

Dukungan support yang terdapat pada project Nagios juga sangat baik. Beragam layanan support mulai dari dokumentasi, FAQ, mailing list, dan forum, sudah disediakan dengan baik oleh pihak Nagios.[9]

\section{E. Paessler Router Traffic Grapher (PRTG)}

PRTG merupakan perangkat lunak yang mudah digunakan untuk memantau penggunaan bandwidth dan banyak parameter jaringan lain melalui SNMP, Packet Sniffing, atau Cisco NetFlow yang memungkinkan untuk pengukuran traffic berdasarkan alamat IP dan atau protokol. Pengukuran berbasis Simple Network Management Protocol (SNMP) hanya berbasis pada port.
Software ini juga memungkinkan untuk secara cepat mempersiapkan dan menjalankan sebuah proses pemantauan untuk sebuah jaringan tertentu. Dengan Paessler Router Traffic Grapher (PRTG) ini maka dengan mudah dapat mengetahui sejumlah data yang mengalir melalui perangkat seperti router dan memamntau penggunaan PC serta menganalisa traffic yang dapat dikategorikan ke dalam beberapa jenis protokol.

Paessler Router Traffic Grapher (PRTG )Traffic Grapher berjalan pada mesin Windows di dalam jaringan selama 24 jam setiap hari dan terus-menerus mencatat penggunaan parameter jaringan. Dengan PRTG Traffic Grapher ini dapat memonitor semua aspek jenis protokol mulai dari jenis jaringan protokol FTP, HTTP, HTTPS, SMTP, ICMP,DNS, POP3, SNMP dan lainnya . disini dapat dilihat seberapa banyak penggunaan bandwith pada masing-masing protokol yang telah ada[6].

\section{F. Open NMS}

OpenNMS dibuat berdasarkan platform java (java-based platform). Persamaan lainnya, keduanya sama-sama merilis dua edisi, open source (free) dan enterprise (commercial). Kendati coverage area service meliputi infrastruktur jaringan, server dan aplikasi, perbedaannya OpenNMS lebih fokus kepada monitoring device jaringan, sementara Hyperic HQ fokus utamanya pada monitoring aplikasi (software).

Sebagaimana umumnya sebuah Network Management System, OpenNMS dibangun menggunakan FCAPS Network Management Model, yaitu sesuai dengan standarisasi yang dikeluarkan ISO/IEC 7498-4. Adapun fitur yang dimiliki oleh OpenNMS, diantaranya Service polling untuk Layanan informasi ketersediaan data dan latensi serta pengukurannya adapun Data collection untuk pengumpulan, penyimpanan dan reporting data yang berasal dari nodes yang dimonitor melalaui protocol, antara lain: SNMP, JMX, HTTP, WMI (Windows Management Instrumentation) dan fitur lain. Pengaturan kejadian baik internal maupun eksternal events, termasuk di dalamnya SNMP traps dan fitur lainya yaitu Alarms and automations - Dilengkapi dengan alarm dengan pengaturan yang outomatis secara terpusat. dan fitur lain yang mendukung yaitu Notifications - Pengiriman pesan berdasarkan kejadian melalui emial, SMS serta media lainnya.[7].

\section{G. The DUDE}

The Dude Network Monitoring adalah alat bantu untuk memonitor aktifitas system dan network infrastruktur, dan secara real-time akan mencatat setiap aktifitas yang terjadi pada perangkat dilingkungan tersebut. Dengan adanya tools ini akan membantu team fault handling dalam hal menganalisa dan menentukan action atau langkah selanjutnya. The Dude memiliki fitur yang sangat lengkap di dalam menunjang kegiatan operational sebuah "Network Operations Center" antara lain adalah Merupakan free software yang disediakan 
oleh MikroTik - atau tidak ber-licenses / ber bayar sehingga siapa saja baik perorangan ataupun kelompok/organisasi dapat menggunakannya secara bebas dan Merupakan free software yang dapat berjalan diatas platform sistem operasi berbasis linux ataupun microsoft windows dan Memiliki fitur dapat membuat peta system dan networks infrastruktur secara automatis ataupun manual dan Memiliki fitur system alert dan log setiap kejadian / event secara realtime terhadap setiap aktifitas perangkat system dan networks infrastruktur dan Memiliki fitur untuk melakukan remote access terhadap perangkat mikrotik ataupun perangkat lain yang terhubung terhadap system dan network infrastruktur yang ada dan Memiliki system pelaporan (reporting) secara real time.[8]

\section{Metodologi}

Penelitian ini merupakan penelitian terapan (applied research) yaitu dengan mempelajari teori-teori penelitian terdahulu (library research), kemudian dilanjutkan dengan terjun kelapangan atau survey langsung (Survey Research), untuk mendapatkan data dalam menentukan kriteria-kriteria yang telah digunakan di perusahaan tersebut, kemudian di kelompokan dan di bentuk kedalam sebuah kuesioner yang digunakan untuk mengumpulkan data sampel dalam waktu tertentu (cross-sectional survey) dari beberapa responden untuk memilih promosi jabatan karyawan pada "PT. TUV".

Kegiatan penelitian ini melalui beberapa tahap dalam pengembangannya yaitu[3]:

1) Studi pendahuluan, Kegiatan yang dilakukan pada saat studi pendahuluan yaitu mengumpulkan materi-materi kepustakaan yang berhubungan dengan pengambilan judul. Kemudian langkah selanjutnya yaitu survey langsung ke tempat penelitian yaitu "PT.TUV", hasil dari survey ini adalah berupa trouble koneksi yang sering terjadi pada perusahaan dan melihat beberapa kriteria yang digunakan untuk penelitian lebih lanjut.

2) Kuesioner. Berdasarkan kebutuhan perusahaan maka dibutuhkan beberapa responden ahli yang expert dibidang jaringan yang terdapat didalam perusahaan tersebut. Langkah selanjutnya adalah menyebarkan kueisoner kepada responden penilai yaitu dengan metode penilaian 360 derajat.

3) Pengolah Data Kuesioner. Setelah kuesioner diisi oleh responden. Maka data diolah menggunakan metode AHP, yaitu pertama kali menggunakan software excel untuk memperhitungkan secara manual gabungan dari beberapa responden untuk dibandingkan dengan penggunaan software. Baru kemudian data yang diperoleh dari perhitungan tersebut dientri kedalam software Expert choice untuk memperoleh hasil akhir berupa alternative terpilih dan bobot penilaian masing-masing kriteria maupun subkriteria.

\section{RANCANGAN MOdEl PEMILIHAN NETWORK MONITORING SYSTEM INFORMASI DENGAN PENDEKATAN AHP PADA PT.TUV}

Karena sulitnya menentukan bobot-bobot ataupun prioritas-prioritas yang sering berubah-ubah, digunakan perbandingan berpasangan yang menggunakan data, pengetahuan, dan pengalaman untuk memperoleh prioritas. Prinsip ini berarti membuat penilaian berkenaan dengan pertimbangan relatif pentingnya satu elemen terhadap yang lain. Untuk itu diperlukan suatu skala perbandingan antar dua elemen, baik secara kualitatif maupun kuantitatif. Dalam penyusunan skala kepentingan atau kesukaan digunakan pedoman dasar sebagai berikut:

TABEL 2.

SKALA PERBANDINGAN BERPASANGAN

\begin{tabular}{|c|c|c|}
\hline $\begin{array}{l}\text { Intensitas } \\
\text { Kepenting } \\
\text { annya }\end{array}$ & Definisi & Penjelasan \\
\hline 1 & $\begin{array}{l}\text { Kedua elemen sama } \\
\text { pentingnya }\end{array}$ & $\begin{array}{l}\text { Dua elemen penyumbangnya } \\
\text { sama besar pada sifat itu }\end{array}$ \\
\hline 3 & $\begin{array}{l}\text { Elemen yang satu } \\
\text { sedikit lebih penting } \\
\text { dari elemen yang } \\
\text { lainnya }\end{array}$ & $\begin{array}{l}\text { Pengalaman dan } \\
\text { pertimbangan dengan kuat } \\
\text { menyokong satu elemen atas } \\
\text { yang lainnya }\end{array}$ \\
\hline 5 & $\begin{array}{l}\text { Elemen yang satu } \\
\text { esensial atau sangan } \\
\text { penting ketimbang } \\
\text { elemen yang lainnya }\end{array}$ & $\begin{array}{l}\text { Pengalaman dan } \\
\text { pertimbangan dengan kuat } \\
\text { menyokong satu elemen atas } \\
\text { yang lainnya }\end{array}$ \\
\hline 7 & $\begin{array}{l}\text { Satu elemen jelas } \\
\text { lebih penting dari } \\
\text { elemen yang lainnya }\end{array}$ & $\begin{array}{l}\text { Satu elemen dengan kuat } \\
\text { disokong, dan dominannya } \\
\text { telah terlihat dalam praktek }\end{array}$ \\
\hline 9 & 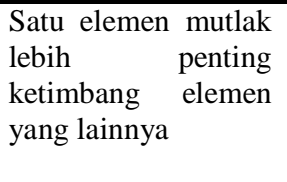 & $\begin{array}{l}\text { Bukti yang menyokong } \\
\text { elemen yang satu atas yang } \\
\text { lain memiliki tingkat } \\
\text { penegasan tertinggi yang } \\
\text { mungkin menguatkan. }\end{array}$ \\
\hline $2,4,6,8$ & $\begin{array}{l}\text { Nilai - nilai diantara } \\
\text { dua pertimbangan } \\
\text { yang berdekatan }\end{array}$ & $\begin{array}{l}\text { Kompromi diperlukan antara } \\
\text { dua pertimbangan }\end{array}$ \\
\hline Kebalikan & \multicolumn{2}{|c|}{$\begin{array}{l}\text { Jika untuk aktivitas i mendapat satu angka bila } \\
\text { dibandingkan dengan suatu aktivitas j, maka j } \\
\text { mempunyai nilai kebalikannya bila dibandingkan } \\
\text { dengan aktivitas } \mathrm{i} \text {. }\end{array}$} \\
\hline
\end{tabular}

\section{A. Hasil Penelitian}

Responden dalam penelitian pemilihan perangkat lunak Network Monitoring System (NMS) ini seluruhnya merupakan responden ahli yang berjumlah 5 (enam) responden. Pengertian responden ahli dalam hal ini adalah seluruh responden sangat memahami networking.

Kelima responden ahli tersebut mewakili 3(tiga) kategori, yaitu Manager,IT staff dan IT support yang terdapat pada perusahaan,baik dikantor pusat maupun dikantor cabang. Berdasarkan hasil penelitian maka dapat dibentuk kerangka rancangan pemilihan network monitoring sebagai berikut : 


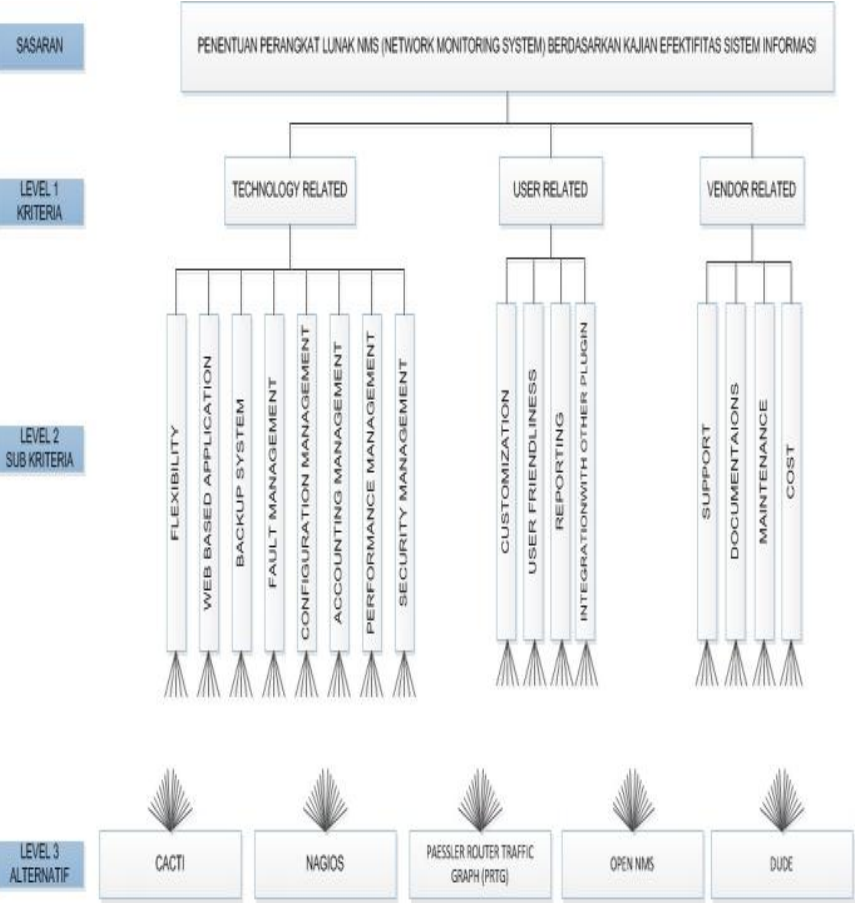

Gambar 3 Kerangka Rancangan Pemilihan Network Monitoring System

Berikut Kriteria yang digunakan untuk kerangka rancangan pemilihan Network Monitoring System pada gambar 3[2].

1) TECHNOLOGY RELATED, yaitu aspek-aspek yang terkait dengan teknologi

2) USER RELATED, yaitu aspek-aspek yang berhubungan dengan pengguna

3) VENDOR RELATED, yaitu aspek-aspek yang berhubungan dengan penyedia perangkat lunak.

Rincian sub kriteria yang dianggap penting yang melandasi ditentukannya perangkat lunak NMS yaitu:

1) Sub Kriteria untuk Kriteria TECHNOLOGY RELATED

a) Flexibility, yaitu fleksibilitas dalam penggunaannya Web Based Application, yaitu perangkat lunak tersebut dapat berjalan dengan tampilan web.

b) Back-up System, yaitu berkaitan dengan backup data

c) Fault Management, yaitu kemampuan dalam mengelola dan mendeteksi kesalahan (error).

d) Configuration Management, yaitu kemampuan dalam memonitor informasi konfigurasi jaringan dan sistem, sehingga semua versi perangkat keras, lunak, dan konfigurasi dapat dilacak.

e) Accounting Management, proses pengukuran utilisasi jaringan sehingga para pengguna jaringan dapat diatur untuk keperluan akunting dan hasil pengukurannya dapat digunakan untuk mendapatkan pola penggunaan jaringan untuk keperluan penjaminan SLA (Service Level Agreement).

f) Performance Management, yaitu kinerja sistem dalam dalam memonitor dan pengelolaan seluruh perangkat jaringan, server, dan aplikasi. g) Security Management, yaitu pengaturan akses terhadap sumber jaringan sesuai dengan aturan yang telah disetujui, sehingga tidak ada user yang tidak memiliki hak akses dapat masuk ke sistem.

2) Sub Kriteria untuk Kriteria USER RELATED

a) Customization, yaitu kemudahan dalam kustomisasi yang disesuaikan dengan kebutuhan pengguna.

b) User Friendliness, yaitu kemudahan dalam penggunaan bagi user.

c) Reporting, yaitu kemampuan menampilakan report yang mudah dibaca oleh pengguna

d) Integration with Other Plugin, yaitu kemampuan integrasi dengan plugin lain untuk memperkaya atau tambahan fitur.

3) Sub Kriteria untuk Kriteria VENDOR RELATED

a) Support, yaitu terkait dari support dari penyedia software yang dalam hal ini biasanya berupa kelompok komunitas pengguna.

b) Documentation, yaitu kelengkapan dokumentasi, baik instalasi maupun pengoperasiannya.

c) Maintenance, yaitu adanya perawatan berupa update sistem.

d) Vendor Credentials, yaitu kredibilitas dari penyedia software.

\section{B. Solusi Dengan Expert Choice 2000}

Hasil perhitungan dengan geometric mean tiap responden,akhirnya digabungkan dan nilai hasil penggabungan tersebut akan dihitung tingkat consistency ratio-nya (CR) menggunakan tool Expert Choice 2000. Berikut hasil yang didapat

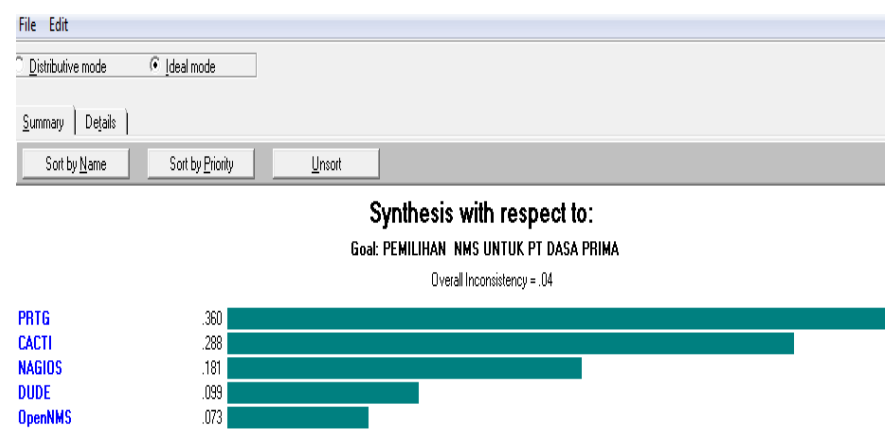

Gambar 4. Hasil Pemilihan Software Monitoring System Berdasarkan Kajian Efektifitas Sistem Informasi

Dari hasil yang tertera di Gambar 4, telah terlihat bahwa software monitoring system untuk Sistem Informasi yang handal adalah PRTG (Paessler Router Traffic Grapher) dengan nilai bobot 0,360 atau sebanding dengan 36,0\% dari total alternatif yang ditetapkan. Hasil nilai bobot alternatif ini ternyata sesuai dengan hipotesa yang dibuat pada perumusan masalah di bab sebelumnya. Kemudian peringkat prioritas alternatif berikutnya adalah CACTI (nilai bobot 28,8\%), NAGIOS (nilai bobot 18,1\%), DUDE (nilai bobot 9,9\%), dan peringkat prioritas terendah adalah OpenNMS (nilai bobot $7,3 \%)$. 


\section{Tingkat Sensivitas Hasil Analisis}

Inconsistency ratio atau rasio inkonsistensi data responden merupakan parameter yang digunakan untuk memeriksa apakah perbandingan berpasangan telah dilakukan dengan konsekuen atau tidak. Rasio inkonsistensi data dianggap baik jika nilai CR-nya $\leq 0.1$. Untuk mengecek rasio inkonsistensi data responden, berikut ini ditampilkan nilai rasio inkonsistensi pada masing-masing matriks perbandingan berdasarkan tabel 3 berikut[2].

\section{TABEL 3.}

RASIO INKONSISTENSI DATA RESPONDEN

\begin{tabular}{|c|c|c|}
\hline No & Matriks perbandingan elemen & $\begin{array}{l}\text { Nilai } \\
\text { CR }\end{array}$ \\
\hline 1 & $\begin{array}{l}\text { Perbandingan elemen kriteria level I } \\
\text { berdasarkan sasaran penentuan perangkat } \\
\text { lunak NMS Berdasarkan Efektifitas Sistem } \\
\text { Informasi }\end{array}$ & 0,06 \\
\hline 2 & $\begin{array}{l}\text { Perbandingan elemen sub kriteria level II } \\
\text { berdasarkan sasaran-kriteria: penentuan } \\
\text { perangkat lunak NMS Berdasarkan } \\
\text { Efektifitas Sistem Informasi Perihal } \\
\text { Technology Related }\end{array}$ & 0,02 \\
\hline 3 & $\begin{array}{l}\text { Perbandingan elemen sub kriteria level II } \\
\text { berdasarkan sasaran-kriteria: penentuan } \\
\text { perangkat lunak NMS Berdasarkan } \\
\text { Efektifitas Sistem Informasi Perihal User } \\
\text { Related }\end{array}$ & 0,05 \\
\hline 4 & $\begin{array}{l}\text { Perbandingan elemen sub kriteria level II } \\
\text { berdasarkan sasaran-kriteria: penentuan } \\
\text { perangkat lunak NMS berbasis Berdasarkan } \\
\text { Efektifitas Sistem Informasi Perihal Vendor } \\
\text { Related }\end{array}$ & 0,08 \\
\hline 5 & $\begin{array}{l}\text { Perbandingan elemen alternatif level III } \\
\text { berdasarkan sasaran-kriteria-sub kriteria: } \\
\text { penentuan perangkat lunak NMS berbasis } \\
\text { Berdasarkan Efektifitas Sistem Informasi } \\
\text { Perihal Technology Related Perihal } \\
\text { Flexibility }\end{array}$ & 0,03 \\
\hline 6 & $\begin{array}{llr}\text { Perbandingan } & \text { elemen alternatif } & \text { level III } \\
\text { berdasarkan } & \text { sasaran-kriteria-sub } & \text { kriteria: } \\
\text { penentuan perangkat lunak } & \text { NMS } \\
\text { Berdasarkan Efektifitas Sistem Informasi } \\
\text { Perihal Technology Related Perihal Web } \\
\text { Based Application }\end{array}$ & 0,08 \\
\hline 7 & 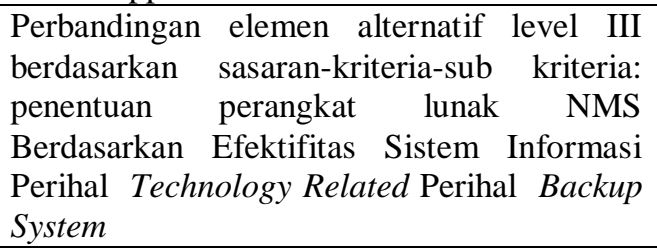 & 0,07 \\
\hline 12 & 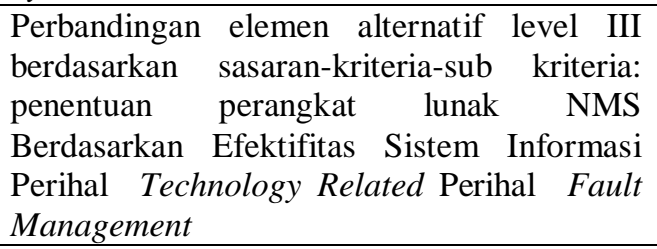 & 0,06 \\
\hline 13 & Perbandingan elemen alternatif level III & 0,06 \\
\hline
\end{tabular}

\begin{tabular}{|c|c|c|}
\hline & $\begin{array}{llr}\text { berdasarkan } & \text { sasaran-kriteria-sub } & \text { kriteria: } \\
\text { penentuan } & \text { perangkat lunak } & \text { NMS } \\
\text { Berdasarkan } & \text { Efektifitas Sistem Informasi } \\
\text { Perihal Technology Related Perihal } \\
\text { Configuration Management }\end{array}$ & \\
\hline 14 & $\begin{array}{lrrr}\begin{array}{l}\text { Perbandingan } \\
\text { berdasarkan }\end{array} & \text { elemen alternatif } & \text { level III } \\
\text { penentuan } & \text { perangkat } & \text { lunak } & \text { NMS } \\
\text { Berdasarkan } & \text { Efektifitas } & \text { Sistem Informasi } \\
\text { Perihal } & \text { Technology } & \text { Related Perihal } \\
\text { Accounting Management } & & \end{array}$ & 0,06 \\
\hline 15 & $\begin{array}{llr}\text { Perbandingan } & \text { elemen alternatif } & \text { level III } \\
\text { berdasarkan } & \text { sasaran-kriteria-sub kriteria: } \\
\text { penentuan } & \text { perangkat lunak NMS } \\
\text { Berdasarkan } & \text { Efektifitas Sistem Informasi } \\
\text { Perihal Technology Related Perihal } \\
\text { Performance Management }\end{array}$ & 0,05 \\
\hline 16 & $\begin{array}{llr}\text { Perbandingan } & \text { elemen alternatif } & \text { level III } \\
\text { berdasarkan } & \text { sasaran-kriteria-sub kriteria: } \\
\text { penentuan } & \text { perangkat lunak } & \text { NMS } \\
\text { Berdasarkan Efektifitas Sistem Informasi } \\
\text { Perihal Technology Related Perihal Security } \\
\text { Management }\end{array}$ & 0,03 \\
\hline 17 & $\begin{array}{llr}\text { Perbandingan } & \text { elemen alternatif level III } \\
\text { berdasarkan } & \text { sasaran-kriteria-sub kriteria: } \\
\text { penentuan } & \text { perangkat lunak NMS } \\
\text { Berdasarkan } & \text { Efektifitas Sistem Informasi } \\
\text { Perihal User Related Perihal Customization }\end{array}$ & 0,04 \\
\hline 18 & $\begin{array}{llr}\text { Perbandingan } & \text { elemen alternatif } & \text { level III } \\
\text { berdasarkan } & \text { sasaran-kriteria-sub } & \text { kriteria: } \\
\text { penentuan perangkat lunak } & \text { NMS } \\
\text { Berdasarkan Efektifitas Sistem Informasi } \\
\text { Perihal User Related Perihal } \\
\text { Friendliness }\end{array}$ & 0,02 \\
\hline 19 & $\begin{array}{llr}\text { Perbandingan } & \text { elemen alternatif } & \text { level III } \\
\text { berdasarkan } & \text { sasaran-kriteria-sub kriteria: } \\
\text { penentuan } & \text { perangkat lunak NMS } \\
\text { Berdasarkan } & \text { Efektifitas Sistem Informasi } \\
\text { Perihal User Related Perihal Reporting }\end{array}$ & 0,03 \\
\hline 20 & $\begin{array}{l}\text { Perbandingan elemen alternatif level III } \\
\text { berdasarkan sasaran-kriteria-sub kriteria: } \\
\text { penentuan perangkat lunak NMS } \\
\text { Berdasarkan Efektifitas Sistem Informasi } \\
\text { Perihal User Related Perihal Integration } \\
\text { with Other plugin }\end{array}$ & 0,09 \\
\hline 21 & $\begin{array}{llr}\text { Perbandingan } & \text { elemen alternatif } & \text { level III } \\
\text { berdasarkan } & \text { sasaran-kriteria-sub kriteria: } \\
\text { penentuan } & \text { perangkat lunak NMS } \\
\text { Berdasarkan } & \text { Efektifitas Sistem Informasi } \\
\text { Perihal Vendor Related } \text { Perihal Support }\end{array}$ & 0,05 \\
\hline 22 & $\begin{array}{llrr}\text { Perbandingan } & \text { elemen } & \text { alternatif } & \text { level III } \\
\text { berdasarkan } & \text { sasaran-kriteria-sub } & \text { kriteria: } \\
\text { penentuan } & \text { perangkat } & \text { lunak } & \text { NMS } \\
\text { Berdasarkan } & \text { Efektifitas } & \text { Sistem Informasi } \\
\text { Perihal } & \text { Vendor } & \text { Related } & \text { Perihal } \\
\text { Documentation } & & \\
\end{array}$ & 0,05 \\
\hline 23 & Perbandingan elemen alternatif level III & 0,08 \\
\hline
\end{tabular}




\begin{tabular}{|c|c|c|}
\hline & \begin{tabular}{lccr} 
berdasarkan & \multicolumn{2}{c}{ sasaran-kriteria-sub } & kriteria: \\
penentuan & perangkat & lunak & NMS \\
Berdasarkan & Efektifitas & Sistem & Informasi \\
Perihal & Vendor & Related & Perihal \\
Maintenance & & &
\end{tabular} & \\
\hline 24 & $\begin{array}{llr}\begin{array}{l}\text { Perbandingan } \\
\text { berdasarkan }\end{array} \text { sasaran-kriteria-sub } & \text { kriteria: } \\
\text { penentuan } & \text { perangkat lunak } & \text { NMS } \\
\text { Berdasarkan Efektifitas Sistem Informasi } \\
\text { Perihal Vendor Related Perihal Vendor } \\
\text { Credentials }\end{array}$ & 0,08 \\
\hline
\end{tabular}

Dapat disimpulkan bahwa perbandingan berpasangan yang diberikan responden ahli memiliki nilai rasio inkonsistensi yang lebih kecil dari 0,1 sebagai batas maksimum nilai rasio inkonsistensi. Dengan demikian hasil perhitungan geometrik gabungan data responden cukup konsisten.

\section{KESIMPULAN}

AHP adalah metodologi pengambilan keputusan untuk multi-atribut dan masalah multi-alternatif. Oleh karena itu metodologi ini,sesuai untuk proses seleksi perangkat lunak, yang merupakan masalah pengambilan keputusan terstruktur, terutama untuk sistem software yang mempunyai banyak variasi dan versi seperti software monitoring jaringan.

Dalam tulisan ini, perangkat lunak Expert Choice 2000 digunakan untuk struktur dan memecahkan masalah. Menggunakan fungsi perangkat lunak untuk mengukur dan menganalisa sensitivitas CR

Akhirnya, tujuan dari penelitian ini adalah untuk menunjukkan bahwa pendekatan sistematis AHP berlaku untuk apapun pengambilan keputusan masalah. Hal ini praktis dan mudah belajar dan metodologi yang dapat meyakinkan pengguna tentang hasil yang wajar.

\section{REFERENSI}

[1] Marimin, (2005), Teknik dan Aplikasi Pengambilan Keputusan Kriteria Majemuk, Jakarta, Cetakan Kedua, Grasindo..

[2] Alanbay, Oyku (2005). ERP SELECTION USING EXPERT CHOICE SOFTWARE. , ISAHP Honolulu, Hawai.

[3] Saaty, Thomas L. (1999). The Essentials of the Analytic Network Process with Seven Examples. Decision Making with Dependency and Feedback: The Super Decisions Software.

[4] Saaty, Thomas L, Vargas Luis G. (2006). Decision Making with The Analytic Network Process. USA : Pittsburgh. PA.

$\begin{array}{llll}\text { [5] (2015) Cacti } & \text { Feature. } & \text { Anailable: }\end{array}$ http://www.cacti.net/what_is_cacti.php

[6] (2015) Paeseler Feature. [Online]. Available: http://www.paeseler.com/

[7] (2015) Open NMS Feature. [Online]. Available: http://demo.opennms.org/opennms/index.jsp

[8] (2015) Mikrotik Feature. [Online]. Available: http://www.mikrotik.com/thedude.php

[9] (2015) Nagios Feature [Online]. Available: https://www.nagios.org

[10] (2008) Internetworking Technology Handbook. Network Management Basics. Available: http://cisco.com/en/US/docs/internetworking/technology /handbook/NM-Basics.html 